\title{
Sarcoidosis of the central nervous system
}

\author{
A. C. DOUGlas AND A. F. J. MALONEY \\ From the Departments of Respiratory Diseases and Neuropathology, \\ University of Edinburgh, Edinburgh
}

SUMMARY Six patients with sarcoidosis of the central nervous system are described. Pathological confirmation was obtained by brain biopsy in two patients and at necropsy in two; in two patients the diagnosis was presumptive and was made on the evidence of multisystem involvement. The symptomatology, methods of diagnosis, and results of treatment are discussed.

Involvement of the central nervous system in sarcoidosis is relatively rare and in the Edinburgh sarcoidosis register of more than 500 cases there are only six examples. These six cases illustrate the infinite variety of the clinical expressions of sarcoidosis of the nervous system, the difficulty in making the diagnosis in the absence of evidence of sarcoidosis in other systems, the chronicity of this form of the disease in most instances, and its variable and usually poor prognosis even when corticosteroid therapy is employed.

\section{CASE REPORTS}

The series consists of four female and two male⿸尸 patients whose ages range from 16 to 55 years. The diagnosis was established by brain biopsy in twe 을 cases, confirmed at necropsy in two cases, and pree sumed in two cases in which multisystem involve ment was proven (Table 1$)$.

TABLE 1

SARCOIDOSIS OF CENTRAL NERVOUS SYSTEM: SUMMARY OF FINDINGS IN SIX PATIENTS

\begin{tabular}{|c|c|c|c|c|c|c|}
\hline Patient & $\begin{array}{l}\text { Age } \\
\text { (yr) }\end{array}$ & Sex & Principal neurological features & Other sarcoid features & Diagnosis & Course \\
\hline D.H. & 44 & $\mathbf{F}$ & $\begin{array}{l}\text { Mental deterioration, headache, } \\
\text { vomiting, papilloedema, } \\
\text { diabetes insipidus }\end{array}$ & $\begin{array}{l}\text { Hilar and cervical } \\
\text { adenopathy, ? nasal } \\
\text { granuloma }\end{array}$ & Biopsy-lymph gland & $\begin{array}{l}\text { Alive } 11 \mathrm{yr}+\text {. Response } \\
\text { to prednisolone }\end{array}$ \\
\hline F.McI. & 38 & $\mathbf{M}$ & $\begin{array}{l}\text { Headache, paraesthesiae, right } \\
\text { facial palsy, epilepsy, mental } \\
\text { deterioration, aphasia, nerve } \\
\text { deafness, optic atrophy }\end{array}$ & $\begin{array}{l}\text { E. N. + hilar adeno- } \\
\text { pathy, cervical } \\
\text { adenopathy, nasal } \\
\text { granuloma, skin } \\
\text { sarcoid }\end{array}$ & $\begin{array}{l}\text { Biopsy-lymph gland, } \\
\text { nasal granuloma, } \\
\text { brain }\end{array}$ & $\begin{array}{l}\text { Progression despite } \\
\text { prednisolone. Died } \\
10 \mathrm{yr}\end{array}$ \\
\hline E.F. & 32 & $\mathbf{F}$ & $\begin{array}{l}\text { Amenorrhoea, diabetes insipi- } \\
\text { dus, headache, epilepsy, } \\
\text { ataxia, meningeal irritation, } \\
\text { coma }\end{array}$ & Nil & Necropsy-CNS & $\begin{array}{l}\text { Died } 2 \text { yr } \\
\text { caemia }\end{array}$ \\
\hline T.C. & 46 & $\mathbf{F}$ & $\begin{array}{l}\text { Right facial palsy, palatal weak- } \\
\text { ness, right hemiparesis, } \\
\text { diplopia, dysarthria, head- } \\
\text { ache }\end{array}$ & Lupus pernio & Presumptive & $\begin{array}{l}\text { Fluctuatıng course, no } \\
\text { treatment, permanent } \\
\text { cerebral damage, alive } \\
13 \mathrm{yr}+\end{array}$ \\
\hline J.O. & 55 & $\mathbf{F}$ & Rapid mental deterioration & Nil & Necropsy-CNS & $\begin{array}{l}\text { Died } 2 \mathrm{mth} \text {, pulmonary } \\
\text { embolism }\end{array}$ \\
\hline J.S. & 16 & $\mathbf{M}$ & $\begin{array}{l}\text { Somnolence, papilloedema, } \\
\text { right hemiparesis, aphasia, } \\
\text { left facial palsy }\end{array}$ & Nil & Biopsy-brain & $\begin{array}{l}\text { Died } 2 \text { yr. Deterioration } \\
\text { despite prednisolone }\end{array}$ \\
\hline & & & & 1024 & & \\
\hline
\end{tabular}




\section{CASE 1}

D.H., a married woman aged 44 years presented in 1961 with mental deterioration, headache, and vomiting and was found to have bilateral papilloedema. A diagnosis of glioma was made and cerebral decompression was carried out using a Spitz-Holter valve. The expected deterioration did not occur and over the next few months she developed enlarged cervical glands, biopsy of which showed features compatible with sarcoidosis. A chest radiograph showed bilateral hilar adenopathy and the Mantoux test was negative to $1: 100$ O.T. The cerebrospinal fluid (CSF) consistently showed a raised serum protein of 200 to $300 \mathrm{mg} / 100 \mathrm{ml}$. but the sugar level was normal and no cells were seen. A diagnosis of neurological sarcoidosis was made and treatment was begun with prednisolone with most gratifying results. On this treatment she became fully conscious and well and the CSF returned to normal. After a year an attempt was made to discontinue the treatment but this was followed by relapse within a month; the patient became drowsy and finally comatose and the CSF protein was again raised. Reintroduction of corticosteroids rapidly restored the status quo. On three occasions over the next two years further attempts were made to withdraw treatment, with similar results each time. At review in 1965 she was also found to have diabetes insipidus and to have gained an undue amount of weight.

The patient remains well with no discernible neurological deficit and her mild diabetes insipidus is under satisfactory control. Treatment with prednisolone is being maintained in a dosage of $10 \mathrm{mg}$ daily.

In 1957 the patient had been found to have atrophic rhinitis which persisted until corticosteroid therapy was begun. Examination in 1965 showed complete absence of the nasal septum and it was believed that the original nasal condition was probably due to sarcoidosis.

SUMMARY A case of CNS sarcoidosis, presumably predominantly meningeal, which was initially misdiagnosed as cerebral tumour. There has been a very satisfactory and maintained response to corticosteroid therapy during eleven years of observation. The CSF showed a raised protein only. There was evidence of multisystem involvement in the form of hilar and cervical adenopathy.

CASE 2

F.McI., a 38 year old male architect, came under observation in June 1958 because of malaise, anorexia, erythema nodosum, and swelling of the ankles and knees of two weeks' duration. The Mantoux test was negative to 1:100 O.T. He improved on treatment with salicylates but four months later again began to feel unwell and was then found to have enlargement of liver and spleen and the chest radiograph now showed bilateral hilar adenopathy. In June 1959 the right posterior auricular

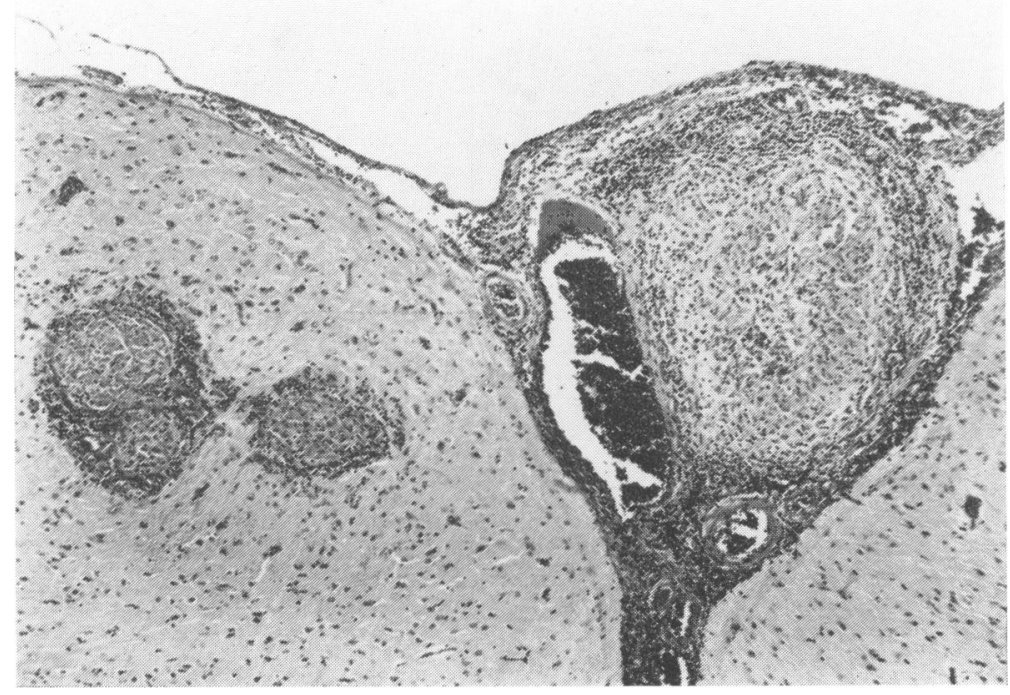

FIG. 1. Cerebral cortex showing sarcoid granulomata in leptomeninges and grey matter. $H$ and $E, \times 50$. 
lymph nodes became enlarged and gland biopsy showed the histological features of sarcoidosis. Corticosteroid therapy was begun and continued for one year, until June 1960 . Three weeks after treatment was stopped he had his first indication of neurological trouble in the form of a sudden attack of altered sensation in the right side of the face, stiffness and numbness of the right thumb and index finger, and some difficulty in finding words. These symptoms were episodic at first, occurring every six to eight weeks or so, lasting about 15 minutes, and followed by left-sided headache for a whole day. Neurological examination showed only brisk reflexes on the right side. The CSF protein was $160 \mathrm{mg} /$ $100 \mathrm{ml}$., the sugar level was normal and there were no cells. He was also found to have a skin sarcoid on the left side of the face. Corticosteroid therapy was resumed and, although the frequency of the initial attacks was reduced, he had two grand mal attacks (in November and December 1961) for which treatment with phenobarbitone and phenytoin was given. Apart from one grand mal seizure in September 1962 he remained fairly well until mid-1963 when he began to have episodes of awareness of a peculiar strong smell, associated with nausea and lasting a few minutes at a time. Over the next few months he had six such attacks and in January 1964 the olfactory aura was followed by major convulsions and a state of altered consciousness with confusion and agitation associated with repeated purposive movements involving rubbing the nose constantly. Over the next few months there were repeated grand mal attacks and he remained confused. He also became disinterested in his person and would not wash himself or change his clothes. His memory gradually deteriorated. In April 1964 he complained of severe nasal congestion and examination showed chronic atrophic rhinitis, biopsy of which showed the features of sarcoidosis. After an episode of status epilepticus in August 1964 he complained of noises in both ears and became deaf so that communication could only be made in writing. Gradually even this became difficult as he developed dysphasia which steadily worsened. In November 1964 he underwent further intensive neurological review. The CSF showed a protein level of $900 \mathrm{ml} . / 100 \mathrm{ml}$., a normal sugar content, and 4 cells/c. $\mathrm{mm}$. There was now bilateral optic atrophy. No localizing information was obtained by electroencephalography (EEG). On 4 December 1964 pneumoventriculography showed symmetrically dilated lateral ventricles. There was persistent non-filling of the left temporal horn which was considered to be abnormal. After this he had persisting hiccups. Radiological screening of the chest showed no abnormality, the previous hilar adenopathy having resolved. On 22 December $196 \$$ left frontotemporal craniotomy and electrocortico graphy were performed. Severe abnormality waș demonstrated all over the exposed area. In addition there were numerous minute $(1 \mathrm{~mm}$ diameter) pale nodules in the leptomeninges, mainly along thê sulci. Subtotal excision of the temporal lobe was performed with partial removal of the middle an inferior part of the frontal lobe.

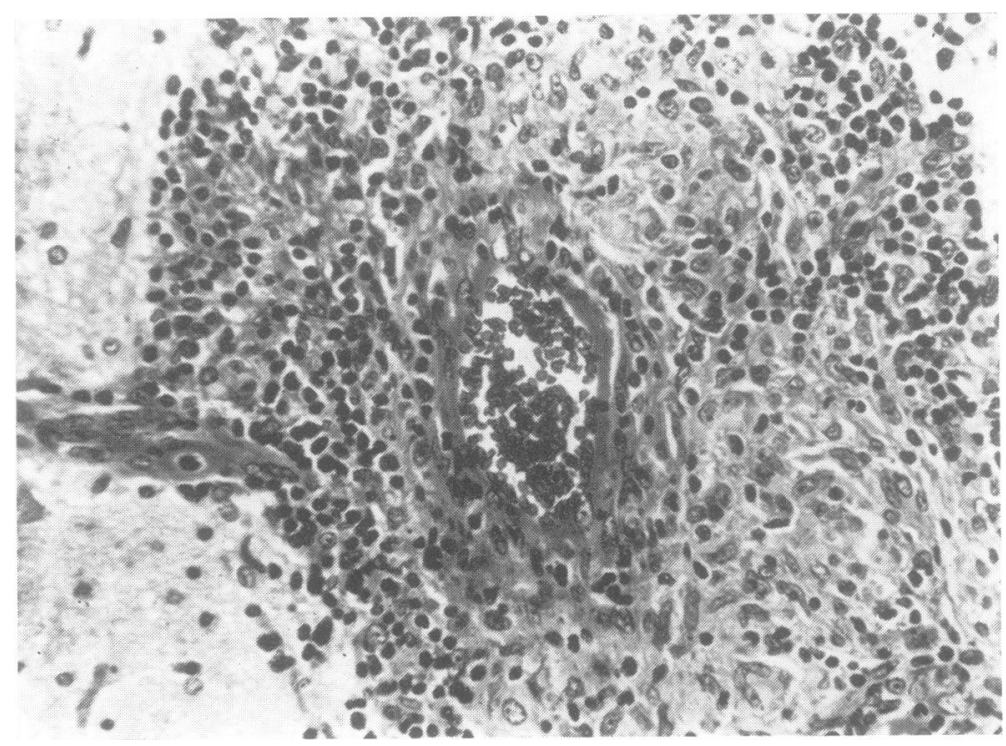

FIG. 2. Blood vessel in centre of sarcoid granuloma showing inflammatory changes in its wall. $H$ and $E, \times 275$. 
Pathological examination of the resected specimen showed numerous minute sarcoid nodules in the leptomeninges and along small penetrating cortical blood vessels (Fig. 1). The blood vessels in relation to the nodules were in the main normal. Occasionally they showed mild infiltration of their walls with chronic inflammatory cells (Fig. 2). The adjacent cortex showed severe focal gliosis. There was some generalized fibrosis of the leptomeninges. The postoperative course was stormy and included tracheostomy because of severe respiratory infection. Eventually he recovered sufficiently to be allowed home where he remained until he died suddenly in 1968. After operation the epileptic attacks were much less frequent and the rate of mental deterioration was slowed. Bilateral deafness remained and speech never recovered. Corticosteroid therapy was continued until death but did not appear to influence the clinical state. There was no necropsy.

SUMMARY A case of meningo-encephalitis due to sarcoidosis proved by cortical biopsy. Neurological features included headache, paraesthesiae, right facial palsy, epilepsy, aphasia, nerve deafness, optic atrophy, and progressive mental deterioration. Multisystem involvement was shown by hilar and cervical adenopathy, nasal granuloma, and skin sarcoid. The course of the disease was apparently uninfluenced by corticosteroid therapy and death occurred eight years after the onset of neurological symptoms. CSF studies showed raised protein with normal sugar and few or no cells.

\section{CASE 3}

Details of E.F., a female aged 32 years, have previously been recorded in detail elsewhere (Schonell et al., 1968). She presented with amenorrhoea and the features of diabetes insipidus followed by headache, epilepsy, meningeal irritation, ataxia, and finally coma and death two years after the onset of neurological phenomena. Corticosteroid therapy supplemented by antituberculosis chemotherapy given towards the end of the illness failed to influence the clinical course, which was complicated terminally by staphylococcal septicaemia. Necropsy showed extensive involvement of the meninges, brain, pituitary gland, and spinal cord with sarcoidosis. There was no evidence at necropsy of sarcoidosis in other systems.

The CSF showed a protein content varying from 700 to $1,800 \mathrm{mg} / 100 \mathrm{ml}$., a glucose level which was normal on three occasions and low $(26 \mathrm{mg} / 100 \mathrm{ml}$.) on one, and no cells.

SUMMARY A case of meningo-encephalomyelitis, with associated hypothalamic lesions, due to sarcoidosis apparently confined to the central nervous system. The CSF showed marked protein increase, a normal or low sugar and no cells. Despite the use of corticosteroids, death occurred two years after the onset of neurological features.

\section{CASE 4}

T.C., a female aged 46 years, had previously been

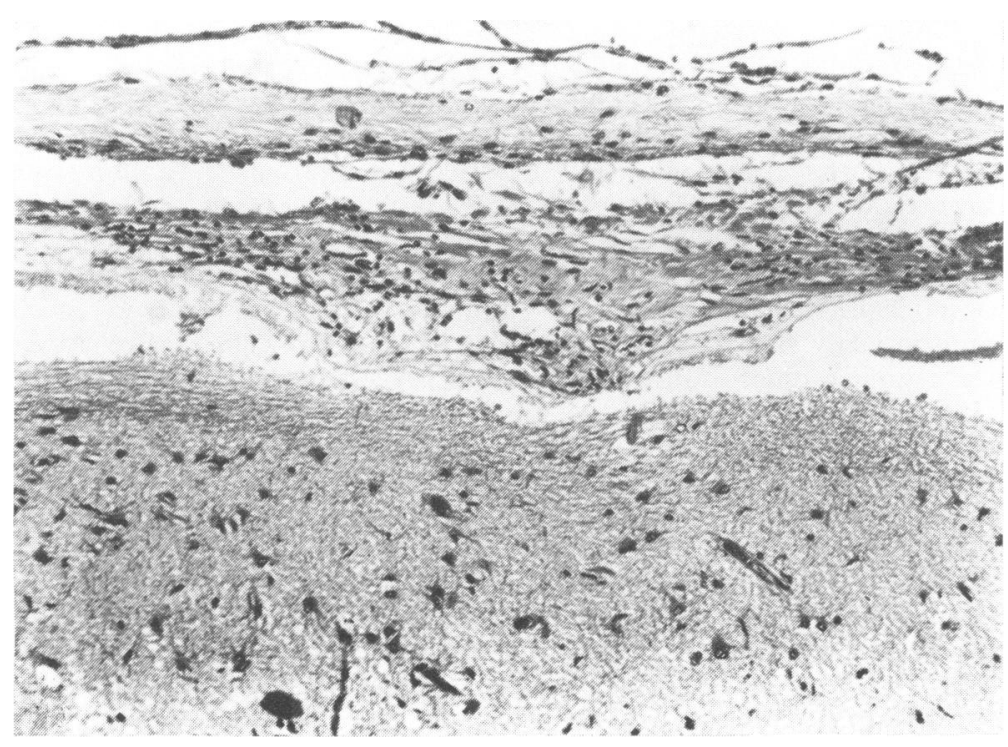

FIG. 3. Cerebral cortex: diffuse and focal meningeal fibrosis accompanied by scanty round cell infiltration. The underlying cortex shows mild diffuse gliosis. $H$ and $E, \times 110$. 
well until in 1959 she developed hypothyroidism which was treated successfully with thyroxine. At this time she first noticed a gradual onset of weakness of the right hand which persisted and about a year later she developed right facial palsy and was also found to have palatal weakness. The CSF was under normal pressure and showed a protein of $80 \mathrm{mg} /$ $100 \mathrm{ml}$., normal sugar, and no cells. The EEG showed gross left-sided abnormality but angiography and air studies did not demonstrate a space occupying lesion. Diplopia, dysarthria, paraesthesiae in the right hand, frontal headache, and worsening of the right-sided weakness developed subsequently and in 1961 she was found to have lupus pernio which was confirmed by skin biopsy. A diagnosis of sarcoidosis having been established, the neurological deficit was attributed to sarcoidosis of the central nervous system. No treatment was given and the condition has pursued a fluctuating course with slow deterioration. The patient is dysphasic but understands spoken speech well, although there is fluctuating impairment of concentration. She is ambulant with the use of a tripod. The EEG has continued to show gross left-sided abnormality but the brain scan is normal.

SUMMARY A case of presumed sarcoidosis of the brain resulting in headache, right facial palsy, palatal weakness, right hemiparesis, diplopia, dysarthria, and dysphasia. The illness has followed a fluctuating course without treatment over 13 years. The CSF showed increase in protein only.

\section{CASE 5}

J.O., a 55 year old married woman, had a 14 year history of rheumatoid arthritis treated with triamcinolone $2 \mathrm{mg}$ per day but was otherwise well until one month before admission to hospital in February 1970 when she had two dizzy attacks, one while out walking when she fell down suddenly and lost consciousness for a few seconds, and the other at home when she had to sit down but did not lose consciousness. On admission she was disorientated in time and place and laughed inappropriately. The cranial nerves were intact and clinical examination of the nervous system was unrevealing. The CSF protein was $67 \mathrm{mg} / 100 \mathrm{ml}$., the sugar level was normal and there were 53 lymphocytes/c. $\mathrm{mm}$. There was no clinical or radiographic evidence of sarcoidosis in any other system. There was rapid mental deterioration over the next two weeks, the patient became febrile and developed a persistent sinus tachycardia. She died suddenly eight weeks after the onset of neurological symptoms.

Necropsy showed that the immediate cause of death was pulmonary embolism. Apart from evidence of rheumatoid arthritis, the major pathological changes were confined to the central nervous system, which showed a chronic granulomatous meningoencephalitis histologically compatible with sarcoidosis. There was no evidence macroscopically or microscopically of sarcoidosis in lymph nodes, lungs, heart, kidney, liver, spleen, or bone marrow.

Examination of the brain after fixation showed slight swelling and a mild meningitis, scanty collections of pale yellow exudate being seen mainly over both cerebral convexities. There was no atheroma. Section showed well-marked uniform dilatation of the entire ventricular system which appeared to be excessive for the degree of atrophy which was undoubtedly present. No focal lesions were seen and there was no evidence of ventriculitis. The cerebellum was normal.

On microscopy there was evidence, in all sections examined, of a chronic granulomatous meningitis superficially resembling tuberculous meningitis. Prolonged search of many sections stained by ZiehlNeelsen's method, however, failed to reveal the presence of any acid-fast bacilli (nor were ans demonstrated in the CSF during life). The amount of exudate was variable and was composed of epi命 윽 thelioid cells, lymphocytes, Langhans type giane cells, and plasma cells. Small ill-defined tuberclese were present in many places and occasionally these showed some degree of central necrosis. Schaumani bodies and asteroids were not seen. Some of the smaller blood vessels in the exudate showed slight intimal fibrosis.

Mild to moderately severe inflammatory changes were seen in the cortex. These were characterized by rod cell reaction, neuronophagia, and perivascular round cell cuffing. No granulomata were seen. Some parts of the cortex appeared normal. Striking changes were also seen in many sections of the white matter, although some areas were normal. The abnormalities included cuffing of blood vessels with chronic inflammatory cells, mainly lymphocytes and a few plasma cells, but also large mononuclear cells with strongly eosinophilic cytoplasm and the presence of small groups of mononuclear cells of like appearance forming tubercles. Giant cells were occasionally seen in relation to these tubercles, but the tubercles did not show central necrosis and were unlike the miliary tubercles of tuberculosis. Where these inflammatory changes were seen the white matter was partially demyelinated.

The alternative diagnoses of tuberculosis, syphilis, fungal and protozoal infection, and malignancy were considered but were ruled out by the combination of clinical, microbiological, serological, and pathological evidence. 
SUMMARY A case of chronic meningo-encephalitis manifested by dizzy attacks and rapid mental deterioration due to sarcoidosis apparently confined to the central nervous system. The CSF showed increase in protein and cells, and a normal sugar.

\section{CASE 6}

J.S., a previously healthy 16 year old boy became suddenly unwell in January 1970 after what appeared to be a bout of influenza associated with a vague abdominal discomfort. After this he became tired and listless and showed a tendency to drag his feet. No obvious abnormality was found on clinical examination but the erythrocyte sedimentation rate (ESR) was $40 \mathrm{~mm}$ per hour. He improved spontaneously and was apparently well until April 1970 when there was a recurrence of abdominal symptoms with vomiting and associated epigastric tenderness. The ESR remained elevated at $60 \mathrm{~mm}$ per hour. He was found to be rather drowsy and to have a mild right hemiparesis and bilateral papilloedema. A history of auditory hallucinations and thought difficulties was also elicited. EEG suggested a left frontal lesion and a radioactive brain scan showed a large area of increased uptake in the left frontal lobe with some diffuse increased activity on the right. The clinical picture suggested a progressive lesion deep in the left frontal region and possibly involving the right side as well. The most likely diagnosis appeared to be a malignant tumour, infiltrating rather than displacing the brain.

In May 1970 brain biopsy was undertaken through a left frontal burrhole. Needle biopsies were obtained at about $5 \mathrm{~cm}$ depth. The lateral ventricle was cannulated and CSF under low pressure was obtained. This showed a protein level of $64 \mathrm{mg} / 100 \mathrm{ml}$., a normal sugar level, and 31 nucleated cells per c. mm, mostly neutrophil polymorphs. Histological examination of several specimens showed the features of a granulomatous meningo-encephalitis compatible with sarcoidosis (Fig. 3). A small area of infarction was seen in one section. Other forms of granulomatous disease were considered but so far as was possible were excluded. Treatment was begun with prednisolone combined with antituberculosis chemotherapy which coincided with initial substantial improvement and for some weeks he was able to lead a reasonably active life, although there was still some weakness in the right leg. In August 1970 there

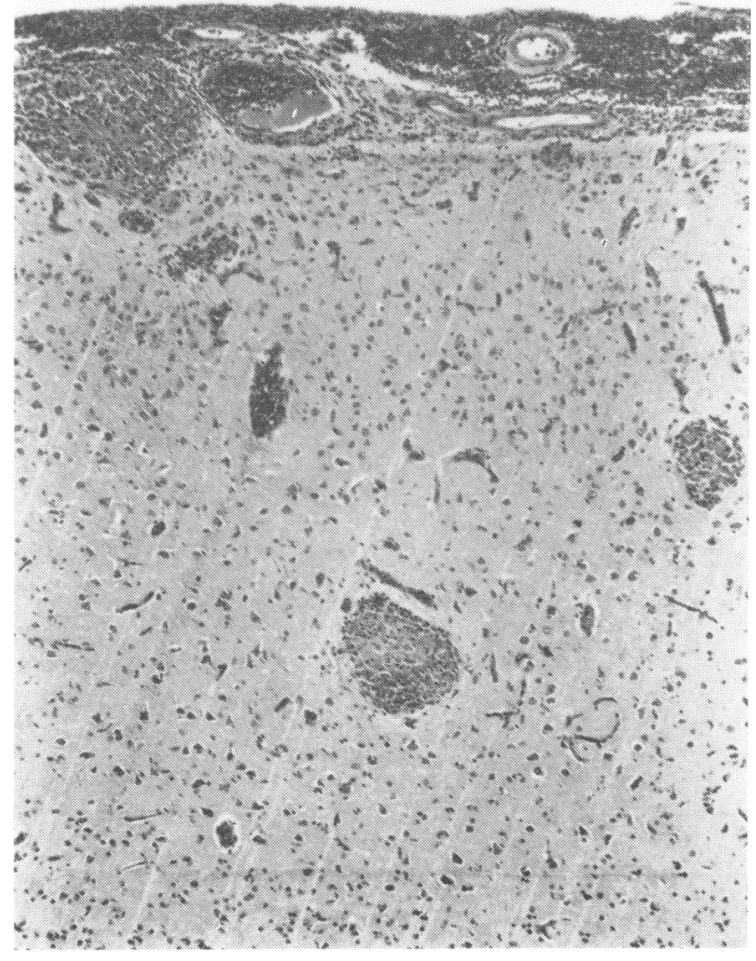

FIG. 4. Scattered sarcoid granulomata in meninges and cortex. Intervening tissue normal. $H$ and $E, \times 50$. 
was sudden deterioration with marked right-sided spasticity, dysphasia, and somnolence. There was also unexplained pyrexia. Although there was some improvement over the next four months, a rightsided spastic hemiparesis and dysphasia persisted and six months later he suddenly developed leftsided hemiparesis and some evidence of pseudobulbar palsy. There was conjugate deviation of the head and eyes to the right side. The patient became incontinent and the pyrexia, which had previously subsided without specific treatment, recurred. On readmission to hospital in July 1971 the patient was almost in a position of opisthotonos. The head was markedly retracted and rotated to the right and the eyes were held in a fixed deviated position to the right side. He appeared to understand simple commands. He tried to speak, but could not. There was very little movement of the palate and pharyngeal sensation was impaired, with a poor gag reflex. The optic fundi were now normal. There was a partial left-sided upper motor neurone facial paresis. The upper limbs were very spastic and were flexed at elbows and wrists. The abdominal muscles were also in marked spasm. The legs were held in an extended spastic position with grossly exaggerated knee jerks and sustained ankle clonus. The plantar responses were extensor. Because of the physical and psychological state it was not possible to carry out full sensory examination but certainly pin prick could be distinguished anywhere over the skin.

Despite continuation of corticosteroid therapy the further progress was downhill and the patient died in October 1971. Permission for necropsy was refused.

SUMMARY A case of histologically proven sarcoidosis of the central nervous system which, despite corticosteroid therapy, followed an inexorable downhill course to death within two years. Among the neurological features there was an upper motor neurone facial paralysis, which has been recorded only rarely (Höök, 1954; Jefferson, 1957). There were no clinical or radiographic indications of sarcoidosis elsewhere but there was no necropsy to prove that this was a case of isolated neurological sarcoidosis. The CSF showed a raised protein, mild pleocytosis and a normal sugar content.

\section{DISCUSSION}

Sarcoidosis affecting the nervous system most commonly results in cranial and peripheral neuropathies; rarely, it involves the central nervous system (Colover, 1948; Pennel, 1951; Meyer et al., 1953; Höök, 1954; Jefferson, 1957 o Reske-Nielson and Harmsen, 1962; Robert 1962; Blain et al., 1965; Daum et al., 1965 Matthews, 1965; Silverstein et al., 1965 Wiederholt and Siekert, 1965; Scadding, 1967 Strickland and Moser, 1967). The neuropathies characteristically occur early in the course of sarcoidosis (when lesions in other systems are

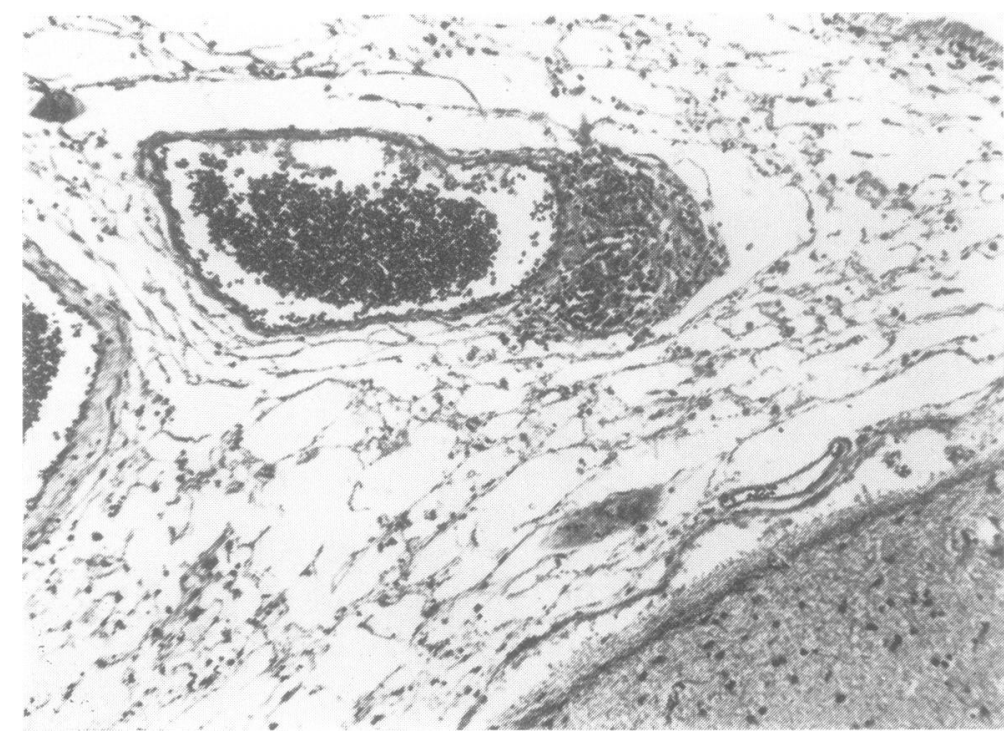

FIG. 5. Sarcoid granulomata involving wall of small meningeal vein. $H$ and $E$, $\times 100$. 
usually obvious), are relatively transient and resolve completely as a rule. Lesions of the central nervous system, on the other hand, tend to develop later in the disease (when multisystem involvement may not be evident), usually pursue a more chronic course, and recover incompletely or even progress despite treatment (Silverstein et al., 1965). The neuropathies and sarcoidosis of the neuraxis are not clinically distinct, however, and central nervous system sarcoidosis is frequently complicated by cranial neuropathies-particularly affecting the seventh nerve-due to involvement of the leptomeninges by sarcoid lesions at the base of the brain.

TABLE 2

SARCOIDOSIS OF CENTRAL NERVOUS SYSTEM: CSF FINDINGS IN SIX PATIENTS

\begin{tabular}{lccl}
\hline Patient & $\begin{array}{c}\text { Protein } \\
(m g / 100 \mathrm{ml} .)\end{array}$ & $\begin{array}{c}\text { Sugar } \\
(\mathrm{N}=\text { normal })\end{array}$ & Cells \\
\hline D.H. & $200-300$ & $\mathrm{~N}$ & 0 \\
F.McI. & 160 & $\mathrm{~N}$ & 0 \\
& 900 & $\mathrm{~N}$ & 4 \\
E.F. & 1,800 & $\mathrm{~N}$ & 0 \\
& 1,000 & $26 \mathrm{mg} / 100 \mathrm{ml}$. & 0 \\
& 700 & $\mathrm{~N}$ & 0 \\
T.C. & 760 & $\mathrm{~N}$ & 0 \\
J.O. & 80 & $\mathrm{~N}$ & 0 \\
J.S. & 67 & $\mathrm{~N}$ & $53(\mathrm{~L})$ \\
\hline
\end{tabular}

Any part of the central nervous system may be involved by sarcoidosis and any aspect of cerebrospinal function can be affected. Thus neurological presentations may vary from impairment of motor power in a limb to disturbance of the central control of respiration (Daum et al.,1965) or even mental deterioration or disorders of personality. The possible combinations of neurological manifestations are legion and there is no constant association of signs or symptoms which can be grouped together to describe a syndrome for sarcoidosis of the central nervous system. Nevertheless, certain combinations of neurological involvement are suggestive-for example, signs of chronic meningitis, diabetes insipidus, facial palsy-and when these occur examination of the CSF is mandatory and the usual investigations for sarcoidosis should be undertaken including a search for sarcoid lesions in other systems and a Kveim test if the tempo of the neurological picture permits. When there is evidence of coexisting sarcoid involvement of other organs, or a past history of this, the diagnosis of central nervous system sarcoidosis presents no great difficulties (Jefferson, 1957) and in this context the presumptive diagnosis of central nervous system sarcoidosis usually proves to be correct. When, however, the neurological features are the only indication of the site of disease the diagnosis becomes a formidable problem. Random tissue biopsy (especially liver and scalene fat pad) may establish the diagnosis but will not if sarcoidosis is confined to the central nervous system (Reske-Nielsen et al., 1962; cases E.F. and J.O.). The value of the Kveim test in sarcoidosis of the central nervous system is limited because it takes four to six weeks to read and is influenced by corticosteroid therapy. Moreover, the positivity rate in sarcoidosis clinically or pathologically confined to the central nervous system is not known. A positive test would, however, be of inestimable value in cases of sarcoidosis presenting only with symptoms and signs of disease of the central nervous system.

Sometimes the diagnosis may be made after histological examination of tissue obtained at craniotomy undertaken to exclude the presence of tumour or for the relief of CSF block. Rarely, a tissue diagnosis is made after elective brain biopsy (Robert, 1962) as in case J.S. reported here. Even the ultimate procedure of brain biopsy may be unhelpful if needle biopsy is the technique used, since the granulomata are frequently widely dispersed (Fig. 4) and a single biopsy may not include pathological tissue. Also, the predominant site of involvement is the base of the brain in most reported cases.

CSF examination may be of great importance in the diagnosis of central nervous system sarcoidosis (Table 2). The most consistent findings are a normal pressure and appearance, raised protein, normal sugar, and a variable number of cells, mainly lymphocytes (Colover, 1948; Pennell, 1951). A low sugar content has been found occasionally (Ernsting and Sillevis Smitt, 1944; Colover, 1948; Pennell, 1951; 
Schonell et al., 1968). Patient E.F., previously reported on by this unit (Schonell et al., 1968), had a CSF protein of $1,800 \mathrm{mg} / 100 \mathrm{ml}$. at one stage, the highest value for protein ever recorded in sarcoidosis of the central nervous system.

Absence of evidence of sarcoidosis in other systems in some cases is not surprising in view of the fact that neuraxis sarcoidosis tends to occur late in the timetable of the disease when coexisting multisystem involvement may be slight and not easily detectable. One would, however expect that multisystem involvement would be proved at necropsy in such cases. In two patients reported here (E.F. and J.O.) full necropsy showed that the central nervous system was the only definable histological site of the disease and 'isolated' sarcoidosis of the central nervous system has also been reported by others (ReskeNielsen et al., 1962). The alternative explanations would appear to be that 'isolated' sarcoidosis in this site is an entity or, as seems much more likely, that preexisting asymptomatic lesions in other systems have resolved without demonstrable trace by the time the neurological lesions become predominant and symptomatic. Obviously there must be great caution about acceptance of a diagnosis of 'isolated' central nervous system sarcoidosis and all alternative diagnoses, including brain tumour, must be thoroughly excluded before applying this label.

Sarcoid lesions have been found in almost every part of the central nervous system and vary from meningeal granulomata to actual tumour-like masses. The affinity of the sarcoid granuloma for cerebral vessels has been stressed by many authors (Longcope and Freiman, 1952; Meyer et al., 1953; Reske-Nielson et al., 1962; Robert, 1962; Urich, 1967) and was striking in the pathological material obtained from the cases reported here (Figs 2 and 5). This probably offers one explanation for the variable response to corticosteroid therapy. Areas of cerebral ischaemia and infarction have been described in relation to granulomatous cerebral angiitis (Meyer et al., 1953) and were found in case J.S. in this series. There was, however, no evidence of thrombosis in any of the involved vessels in our cases. The development of meningeal fibrosis (Fig. 3) is another feature which may determine progression of neurological phenomena and limit response to corticosteroid drugs; it may sometimes compel surgical treatment for relief of hydrocephalus or of intractable epilepsy.

The course of central nervous system sarcoidosis is unpredictable but it is generally agreed that involvement of the central nervous system indicates the use of corticosteroid therapy as the only hope of influencing the disease and modifying its effects on function. To be maximally effective, treatment should be begun early. Sometimes corticosteroids have to be used on a probability basis when there are life-threatening neurological manifestations which do not conform to any clear disease pattern. No matter how long the neurological features have been present corticosteroid therapy should be tried. In the patient with the Guillain-Barré syndrome due to sarcoidosis reported by Strickland et al. (1967) an excellent result was obtained when treatment was begun two years after the onset of symptoms. Improvement does not always follow and there may be deterioration despite corticosteroid therapy (patients F.McI. and J.S.). If improvement does occur extreme caution must be observed when making reductions in dosage (patient D.H.); treatment may require to beo continued indefinitely.

By analogy with asymptomatic and symptom atic skeletal muscle involvement in sarcoidosis it is reasonable to postulate that in the common forms of subacute, transient sarcoidosis there may be involvement of the central nervous system to a degree insufficient to disturb function and that this resolves with no discernible residual damage. Why it is that the diffuse granulomatous process should become dominant in one organ or system remains one of the many inexplicable features of the disease.

We wish to thank Mr. Phillip Harris for permission to publish case F.McI., Dr. J. B. McGuinness for permission to publish case J.S., and Dr. D. C. Bouch for the necropsy report on case J.O.

\section{REFERENCES}

Blain, J. G., Riley, W., and Logothetis, J. (1965). Optic nerve manifestations of sarcoidosis. Archives of Neurology, 13, 307-309.

Colover, J. (1948). Sarcoidosis with involvement of the nervous system. Brain, 71, 451-475.

Daum, J. J., Canter, H. G., and Katz, S. (1965). Central nervous system sarcoidosis with alveolar hypoventilation. American Journal of Medicine, 38, 893-898.

Ernsting, W., and Sillevis Smitt, W. G. (1944). Neurologische 
verschijnselen bij de ziekte van Besnier-Boeck-Schaumann. Geneeskundige Bladen uit Kliniek en Laboratorium voor de Praktijk, 41, 1-40.

Höök, O. (1954). Sarcoidosis with involvement of the nervous system. Report of nine cases. Archives of Neurology and Psychiatry, 71, 554-575.

Jefferson, M. (1957). Sarcoidosis of the nervous system. Brain, 80, 540-556.

Longcope, W. T., and Freiman, D. G. (1952). A study of sarcoidosis. Medicine (Baltimore), 31, 1-132.

Matthews, W. B. (1965). Sarcoidosis of the nervous system. Journal of Neurology, Neurosurgery, and Psychiatry, 28, 23-29.

Meyer, J. S., Foley, J. M., and Campagna-Pinto, D. (1953). Granulomatous angiitis of the meninges in sarcoidosis. Archives of Neurology and Psychiatry, 69, 587-600.

Pennell, W. H. (1951). Boeck's sarcoid with involvement of the central nervous system. Archives of Neurology and Psychiatry, 66, 728-737.

Reske-Nielsen, E., and Harmsen, A. (1962). Periangiitis and panangiitis as a manifestation of sarcoidosis of the brain: report of a case. Journal of Nervous and Mental Diseases, $135,399-412$.
Robert, F. (1962). Sarcoidosis of the central nervous system. Report of a case and review of the literature. Archives of Neurology, 7, 442-449.

Scadding, J. G. (1967). Sarcoidosis, pp. 272-290. Eyre and Spottiswoode: London.

Schonell, M. E., Gillespie, W. J., and Maloney, A. F. J. (1968). Cerebral sarcoidosis. British Journal of Diseases of the Chest, 62, 195-199.

Silverstein, A., Feuer, M. M., and Siltzbach, L. E. (1965). Neurologic sarcoidosis. Study of 18 cases. Archives of Neurology, 12, 1-11.

Strickland, G. T., Jr., and Moser, K. M. (1967). Sarcoidosis with a Landry-Guillain-Barré syndrome and clinical response to corticosteroids. American Journal of Medicine, 43, 131-135.

Urich, H. (1967). Pathological observations on six cases of cerebral sarcoidosis. In La Sarcoïdose. Rapports de la IVe Conférence Internationale, Paris, 1966, pp. 591-593. Masson: Paris.

Wiederholt, W. C., and Siekert, R. G. (1965). Neurological manifestations of sarcoidosis. Neurology (Minneapolis), 15, $1147-1154$ 